\title{
Growth Model and Forecasting Prices of Some Agricultural Products in Bangladesh
}

\author{
Mohammad Abdullah Al Mamun ${ }^{1}$, Mohammad Zakir Hossain², Sheikh Mohammad Sayem³, \\ and Khondaker Md. Mostafizur Rahman ${ }^{4}$

$$
\text { محمد عبدج النمو والتنبؤ بأسعار بعض المنتجات الزوراعية في بنغلاديش، محمد زاكر حسين، شيخ محمد سايم وخوندكر محمد مصطفيز رحمان }
$$

ABSTRACT. The aim of this paper was to explore the appropriate deterministic time series model using the latest selection criteria considering the price pattern of onion, garlic and potato products in Bangladesh (January 2000 to December 2016). It appeared from our analysis that the time series data for the prices of potato was first order homogenous stationary but onion and garlic were found to be the second order stationary. Four different forecasting models namely, linear trend model, quadratic trend model, exponential growth model, and S-curve trend model were used to find the best fitted model for the prices of above mentioned products in the Bangladesh. Three accuracy measures such as mean absolute percentage error (MAPE), mean absolute deviation (MAD) and mean squared deviation (MSD) were used for the selection of the best fitted model based on lowest value of forecasting error. Lowest values of these errors indicated a best fitted model. After choosing the best growth model by the latest model selection criteria, prices of selected agricultural commodities were forecasted using the following time-series analysis methods: Simple Exponential Method, Double Exponential Method using the time period from January 2017 to December 2021. The findings of this study would be useful for policy makers, researchers, businessmen as well as producers in order to forecast future prices of these commodities.

KEYwORDS: Agricultural commodity prices, Forecasting, Growth models, Time series models, Model selection criteria, Accuracy measures.

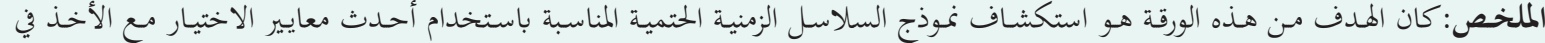

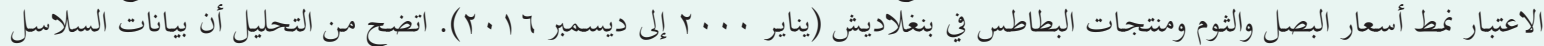

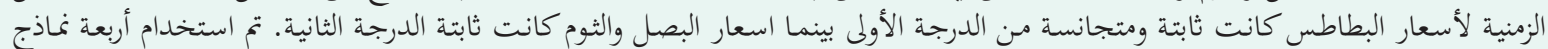

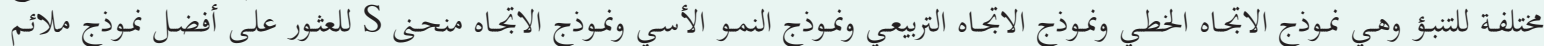

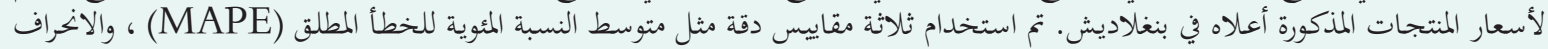

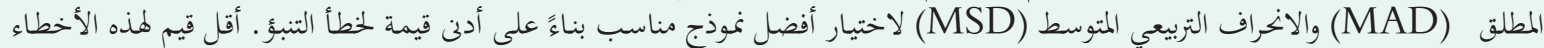

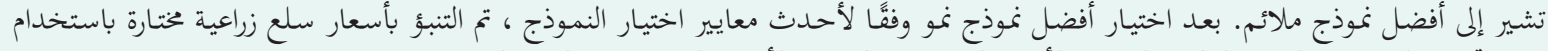

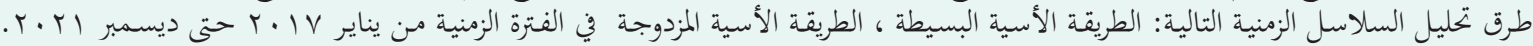

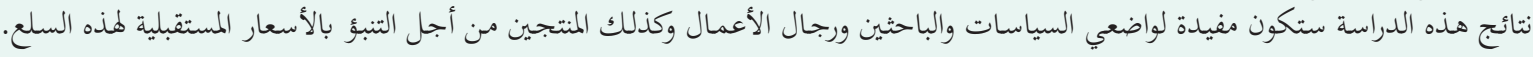

$$
\begin{aligned}
& \text { الكلمات المفتاحية: أسعار السلع الزراعية، التنبؤ، نماذج النمو، نماذج السلاسل الزمنية، معايير اختيار النموذج، مقاييس الدقة. }
\end{aligned}
$$

\section{Introduction}

$\mathrm{B}$ angladesh is an agro-based developing country and striving hard for rapid development of its economy. Agriculture is the mainstay of Bangladesh economy and it contributes about $16.3 \%$ of the gross domestic product (GDP) (BBS, 2014). Potato ranks fourth in the world (325.3 million tons). The potato production ( 8.0 million tons) is among all the vegetables in respect of area coverage and production; and it contributes $55 \%$ of the total vegetable production in Bangladesh (BBS, 2009). It is one of the leading vegetable crops to fulfill the demand of carbohydrate in Bangladesh. Onion is one of the most important spice crops and currently it is cultivated in 0.128 million hectares of land and around

Mohammad Zakir Hossain $2^{\circ}(\checkmark)$ mzhossain@squ.edu.om, College of Economics and Political Science, Sultan Qaboos University, Muscat, Oman.
1.1 million metric tons are produced with average yield of 8.25 tons/ha. Potato contains $62 \%$ water, $29.8 \%$ carbohydrates, $6.3 \%$ protein, $0.1 \%$ mineral, $0.4 \%$ fibers and vitamin C. Among the bulb spices, garlic ranks the third in terms of planting area (37072 hectares) and production (164392 metric tons) and its cultivation covered 7\% of the total area used for spices. The average yield of garlic is 4.43 metric tons per hectare (BBS, 2010). Considering the price scenario, proper understanding of agricultural price mechanism and their forecasts can help the farmers in many ways such as: (i) plan and decide about the production portfolio, (ii) develop marketing strategy to improve profits, (iii) traders to know the market trends and, (iv) Government to augment economic developments in the nation.

The policy makers of the country needs an accurate early information about the status of different crops such as onion, garlic and potato. Therefore, accurate 
forecasting prices of agricultural products support the policy makers and planners to make policy decision regarding supply, demand and import/export of potato in the country. A number of work have been done by researchers on the forecasting prices and production of rice, wheat, maize, sugarcane and different types of pulses. However, negligible work have been reported on the three important food products, e.g., onion, garlic and potato in Bangladesh. A number of forecasting models for projecting the agricultural crops and vegetables have been used earlier. Hassan et al. (2013) worked on forecasting coarse rice in Bangladesh using deterministic trend models (e.g. linear, quadratic and cubic) and it revealed that cubic model was the best fitted model for projecting agricultural grain on the basis of model selection criteria namely, $\mathrm{R}^{2}$ (coefficient of determination), $\bar{R}^{2}$ (adjusted coefficient of determination), RMSE (root mean squared error), AIC (Akaike information criterion), BIC (Bayesian information criterion), MAE (mean absolute error) and MAPE (mean absolute percentage error). Rahman et al. (2013) determined best fitted growth model on forecasting of pulse production in Bangladesh. They used growth model and it revealed that the cubic model was found to be the best model for pigeon pea, chickpea and field pea pulse production. Akhter (2013) conducted a research on forecasting of rice production in Bangladesh and it revealed that both the quadratic linear and cubic models were proved to be the equally better fitted models for rice production in Bangladesh. A very common practice to estimate the growth rate of rice production using accuracy model namely, exponential or compound model (Akhter and Jaim, 2002; Barua and Alam, 2000; Jabber and Jones, 1997). Karim et al. (2010) had worked on the forecasting of wheat production in Bangladesh. Furthermore, Abid et al. (2018) had completed a research on exponential growth model for forecasting of growing area and production of potato crops in Pakistan. In fact, it is necessary to estimate the growth model that best fits the time series data before performing growth analysis.

From the multiple literature review on forecasting determination models, it showed that research work have been completed on forecasting of onion, garlic and potato production in daily/month/yearly production data set basis using multiple determination time series model. Wholesale price of rice, spice crops including masur, gram, kheshari, field pea, black gram and mung bean had been completed using accuracy model estimation (Rahman et al., 2013). But there is negligible work on forecasting prices of three important commodities namely, onion, garlic and potato in the context of Bangladesh. Due to the escalation of prices of vegetables and spice crops, price determination is difficult to maintain equilibrium position of demand and supply in competitive market. Government is always anxious about how to determine price equilibrium in order to make the seller and buyer equally benefited; and produc- er can earn maximum profits for their products. In this context, early forecasting about the probable prices of vegetables and spice crops could help the policy makers to predict the probable prices of their desired product. Forecasting is very important in decision making cases at all levels in different economic sectors; particularly in agriculture sector. In this sector, the policies and decisions are characterized by risks and uncertainty largely due to varied yields, and relatively low price elasticity of demand. To reveal the price pattern and to make the best forecast prices of the selected products, appropriate time series models based on the observed data are necessary. Deterministic type of time series models, often called growth models, such as linear, quadratic, cubic, exponential, compound, inverse, power, and $\mathrm{S}$-shaped are very quick to estimate, inexpensive and easy to understand. Therefore, these models are widely used to estimate the growth rate of time series data. Before performing growth analysis it is necessary to identify the growth model that best fits the time series data. In this paper, an attempt is made to identify the best models for the three selected agricultural commodity prices in Bangladesh using the latest available criteria, such as MAPE, MAD (Mean Absolute Deviation), and MSD (Mean Squared Deviation) (Gujarati, 2016). In this paper, another attempt is made to describe the growth scenario in order to forecasts of the prices of these three important commodities in Bangladesh.

\section{Data and Methodology}

The present study was conducted using secondary time series data on the prices of three commodities namely, potato, onion and garlic in Bangladesh (January 2000 to December 2016). The monthly data of the wholesale prices of the three commodities (Tk. per quintal) from the year January 2000 to December 2016 were collected from Department of Agricultural Marketing (DAM), Food Planning and Monitoring Unit (FPMU) under the Ministry of Food System Management Division. These secondary data were used to analyze and achieve the specific objectives of this study.

In this study, the growth models were used to describe the behavior of variable changing with respect to time. Integrated variable exhibited a systematic variation or trend. If the trends are completely predictable, it is called as deterministic trend. The specification of a deterministic trend can be functional form of time. The mathematical form of deterministic trend can be as follows:

$y=\alpha+\beta t$

It is important to note that this type of model is called deterministic in which no reference is made to the source and nature of the underlying randomness in the series. Forecasts obtained by this particular model can often be usefully combined with oth- 
er forecasts in order to get overall superior forecasts.

\section{Analytic Techniques}

Four different forecasting models (i.e., linear trend model, quadratic trend model, exponential growth model, and S-curve model) were used to find the best fitted model for area and production of potato, onion and garlic in Bangladesh (Khan et al., 2014). The following forecasting models were used:

Liner Trend Model:

$Y=\alpha+\beta t+\epsilon$

Quadratic Trend Model:

$Y=a+b t+c t^{2}+\epsilon$

Exponential Growth Model:

$Y=d[\exp (f t \epsilon)]$

S-Curve Model (Pearl-Reed logistic trend model):

$Y=\frac{10^{g}}{k+l m^{t}}$

where, $Y$ is the time series considered, $t$ represents time taking integer values starting from $1, \epsilon$ is the regression residual, $\alpha, \beta, a, b, c, d, f, g, k, l, m$ are the coefficients of the models.

\section{Criteria Used for Model Selection}

In the case of two or more competing models for conducting the diagnostic checks, the best model is selected by using the criteria such as MAPE, MAD and MSD. The definition and some related materials are briefly given in the following sections.

\section{Exponential Smoothing}

Exponential Smoothing Methods (ESM) are a family of forecasting models. They use weighted averages of past observations to forecast new values. This method was initially developed by Robert G. Brown and further developed by the forecasting inventory control systems. Exponential Smoothing is a forecasting method that the observed time series data are weighted unequally. Two types of exponential smoothing models are widely used namely, Simple Exponential Smoothing (SES) and Double Exponential Smoothing (DES). Simple Exponential Smoothing, SES for short, is a time series forecasting method for univariate data without a trend or seasonality. It requires a single parameter, called $\alpha$, also called the smoothing factor or smoothing coefficient. This parameter controls the rate at which the influence of the observations at prior time steps decay exponentially. The value of $\alpha$ is often set to a value between 0 and 1. Large values mean that the model pays attention mainly to the most recent past observations, whereas smaller values mean more of the history is taken into account when making a prediction. A value close to 1 indicates fast learning (that means, only the most recent values influence the forecasts), whereas a value close to 0 indicates slow learning (past observations have a large influence on forecasts). Formula for Simple Exponential Smoothing is:

$\hat{P}_{t+1}=\alpha P_{t}+(1-\alpha) \hat{P}_{t}$

where $\hat{p}_{t+1}$ is the forecast prices at time $\mathrm{t}+1 ; \mathrm{P}_{\mathrm{t}}$ is the actual price at time $\mathrm{t}$; (obervered); $\hat{p}_{t}$ is the forecast of $P_{i}$, and $0<\alpha<1$ is the smoothing parameter. Double Exponential Smoothing is an extension to Exponential Smoothing that explicitly adds support for trends in the univariate time series. Double Exponential Smoothing (DES) computes a trend forecasting equation by applying a special weighting function and emphasizing on the most recent time periods. This method supports the trends that change in two ways: an additive and a multiplicative, depending on whether the trend is linear or exponential, respectively. The DES makes use of the following formulas:

$\hat{P}_{t}=\alpha P_{t}+(1-\alpha)\left(\hat{P}_{t-1}+b_{t-1}\right)$

$b_{t}=\gamma\left(\hat{P}_{t}-\hat{P}_{t-1}\right)+(1-\gamma) b_{t-1}$

$F_{t+m}=\hat{P}_{t}+b_{t} m$

In the DES method, the most decisive parameters are smoothing constants $\alpha$ and $\gamma$ both of which belong between 0 and 1 . The forecasts generated by Holt's linear method display a constant trend (increasing or decreasing) indecently into the future. Mean Square Error (MSE) has the same unit of measurement as the square of the quantity being estimated. It is defined as:

$M S E=\frac{1}{n-k} \sum \hat{u}_{t}^{2}$

where, $n$ is the sample size, $k$ is the total number of estimable parameters and $\hat{\mathrm{u}}_{t}$ is the difference between the observed and estimated values. The model with minimum MSE is assumed to describe the data series more adequately. Root Mean Square Error (RMSE) is defined as:

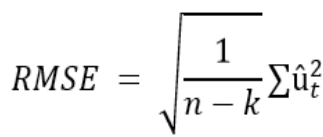

where, $n$ is the sample size and $\mathrm{k}$ is the total number 
of estimable parameters and $\hat{\mathrm{u}}_{t}$ is the difference between the observed and estimated values. The model with minimum RMSE is assumed to describe the data series more adequately. Mean Absolute Deviation (MAD) is an average of absolute deviations of individual observations from the central value of a series. It is defined as:

$\operatorname{MAD}(\bar{x})=\frac{\sum_{t=1}^{n}\left|x_{t}-\bar{x}\right|}{n}$

where $u_{t}=x_{t}-\mathrm{x}^{-}$, which stands for the deviations of the individual observations from the mean, and absolute means that the signs of the deviations whether positive or negative are ignored. Mean Absolute Percent Error (MAPE), the fourth model selection criterion is defined as:

$M A P E=\frac{1}{n} \sum_{t=1}^{n}\left|\frac{\hat{\mathrm{u}}_{t}}{Y_{t}}\right| \times 100$

where $n$ is the number of observations, $Y_{t}$ is the observed value and $u_{t}$ is the difference between the observed and estimated values.

\section{Results and Discussion}

\section{Stationary Test}

Since the data series was found to be non-normal, Augmented Dickey Fuller (ADF) test was conducted to make the series stationary. The results indicated that the series was made stationary at 1 st order difference and $2^{\text {nd }}$ order difference with p-value of $0.01,0.05,0.10$ levels of significance. The trend component of the data was removed in order to make it suitable for price forecasting.

\section{Model Selection Criteria}

Model selection is an important part of any statistical analysis. The models considered for this study were estimated for the monthly wholesale prices of potato in Bangladesh during January 2000 to December 2016. All the model selection criteria were used in this study to identify the best fitted model for forecasting purpose and also for explaining the growth patterns of the commodities. Interpretation of the model selection criteria is considered based on the lowest value of MAPE, MAD, and MSD.

\section{Diagnostic Measures for the Selection of the Best Fitted Model}

From Table 1, it is clearly appeared that for onion, the values of MAPE, MAD and MSD are 28, 656, 1023026, respectively; for garlic, the values of MAPE, MAD and MSD are 32, 1751, and 7845835, respectively; and for potato, the values of MAPE, MAD and MSD are 31, 353, and 211023, respectively, all of which are smaller for ex- ponential model as compared to other growth models. Therefore, the exponential growth model was found to be the best fitted model for the trend analysis on the prices of these three agricultural products. It is on the basis of smaller values of accuracy and thus this model is being selected as a best model for forecasting. From Figure 1 we see that the graphs of actual prices and predicted prices for three selected commodities are slightly fluctuated at time. As the actual values and predicted values showing similar seasonal cyclical pattern, therefore it clearly indicates that the exponential model is more suitable for forecasting.

The Figure 2 is constructed between actual prices and predicted prices of onion, potato and garlic. In comparison to the actual prices and predicted prices for onion, the prices of onion are accounted for Tk. 1344/100 $\mathrm{kg}$ to Tk. $<2000 / 100 \mathrm{~kg}$ (Jan-2000 to May-2005), Tk. $1214 / 100 \mathrm{~kg}$ to Tk. $8000 / 100 \mathrm{~kg}$ (June-2005 to Jan-2014), Tk. $<2000 / 100 \mathrm{~kg}$ to Tk. $6000 / 100 \mathrm{~kg}$ (Feb-2014 to Jan2016). In the comparison to the actual prices and predicted prices for garlic, the prices of garlic are accounted for Tk. 5000/100 kg to Tk.10000/100 kg (Jan-2000 to April-2007), Tk. $<5000 / 100 \mathrm{~kg}$ to $>10000 / 100 \mathrm{~kg}$ (May2007 to Jan-2010), Tk. $<20000 / 100 \mathrm{~kg}$ to Tk.15000/100 $\mathrm{kg}$ (Feb-2000-Dec-2016). In comparison to the actual prices and predicted prices of potato, the prices of potato are accounted for Tk.1000/100 kg to Tk.2000/100 kg (Jan-2000 to sep-2006), Tk. <2000/100 kg to Tk. $<3000 / 100 \mathrm{~kg}$ (Oct-2006 to Sep-2009), Tk. 2000/100 kg to Tk. $3000 / 100 \mathrm{~kg}$ (Oct-2009 to Dec-2015), Tk.1000/100 $\mathrm{kg}$ to Tk. 2000/100 kg (Jan-2016 to Dec-2016). The comparison of actual prices and predicted prices show similar value and the seasonal cyclical pattern is shown upturn and downturn with time. Since actual price and predicted price are shown similar value, it is ready to better forecasting.

In Figure 3, we constructed a line graph for comparing the predicted prices and residuals for accuracy of forecasting for our selected three agricultural commodities. Residual values mean the difference between the predicted values and observed values. In residual, if the prices of three commodities are equal to zero, this line is actually the best fitted line. In the predicted prices and residual for onion, the prices of onion is equal to zero or close to zero. The predicted prices is shown upturn and downturn pattern which accounted for Tk. $1344 / 100 \mathrm{~kg}$ to Tk. $<4000 / 100 \mathrm{~kg}$ (Jan-2000 to Nov2005), Tk. $<2000 / 100 \mathrm{~kg}$ to Tk.8000/100 kg (Dec-2005 to Jan-2014), respectively. Similarly, the predicted prices of garlic and potato are shown upturn and downturn in a graph where residual is equal to zero or close to zero. Thus it is clear that we are estimating best fitted model for forecasting using data set from January 2000 to December 2016.

In Figure 4, forecasted prices (Jan-2017 to Dec 2021) of our selected three agricultural products have been estimated based on the actual prices of commodities from 
Table 1. : Criteria for best fitted model prices of the Agricultural products (Onion, Garlic and Potato) with comparison accuracy measurements among trend models.

\begin{tabular}{|c|c|c|c|c|c|}
\hline & Model & Fitted Trend Equation & \multicolumn{3}{|c|}{ Accuracy Measures } \\
\hline \multirow{6}{*}{ Onion } & & & MAPE & MAD & MSD \\
\hline & Linear & $Y=981+13.19 t$ & 31 & 668 & 986716 \\
\hline & Quadratic & $Y=1006+12.46 t+0.0035 t^{2}$ & 31 & 668 & 986594 \\
\hline & Exponential & $\mathrm{Y}=1129.92 \times\left(1.00588^{\mathrm{t}}\right)$ & 28 & 656 & 1023026 \\
\hline & S Curve & $Y=\left(10^{5}\right) /\left[24.4701+8.0844 \times\left(0.988668^{t}\right)\right]$ & 27 & 649 & 1080658 \\
\hline & Trend & Fitted Trend Equation & \multicolumn{3}{|c|}{ Accuracy Measures } \\
\hline \multirow{7}{*}{ Garlic } & & & MAPE & MAD & MSD \\
\hline & Linear & $Y=2256+29.36 t$ & 38 & 1862 & 7555079 \\
\hline & Quadratic & $\mathrm{Y}=2495+22.4 \mathrm{t}+0.0340 \mathrm{t}^{2}$ & 37 & 1852 & 7543983 \\
\hline & Exponential & $Y=2619.46 \times\left(1.00539^{t}\right)$ & 32 & 1751 & 7845835 \\
\hline & S Curve & $\mathrm{Y}=\left(10^{5}\right) /\left[18.2718+33.2841 \times\left(0.975665^{t}\right)\right]$ & 33 & 1887 & 9078596 \\
\hline & Trend & Fitted Trend Equation & \multicolumn{3}{|c|}{ Accuracy Measures } \\
\hline & & & MAPE & MAD & MSD \\
\hline \multirow{4}{*}{ Potato } & Linear & $Y=582.6+6.417 t$ & 33 & 355 & 204289 \\
\hline & Quadratic & $Y=596.1+6.02 t+0.0019 t^{2}$ & 33 & 355 & 204253 \\
\hline & Exponential & $Y=629.132 \times\left(1.00552^{t}\right)$ & 31 & 353 & 211023 \\
\hline & S Curve & $Y=\left(10^{4}\right) /\left[7.10205+18.4221 \times\left(0.971589^{t}\right)\right]$ & 32 & 378 & 238562 \\
\hline
\end{tabular}

Data Source: Department of Agricultural Marketing (DAM) during 2000 to 2016

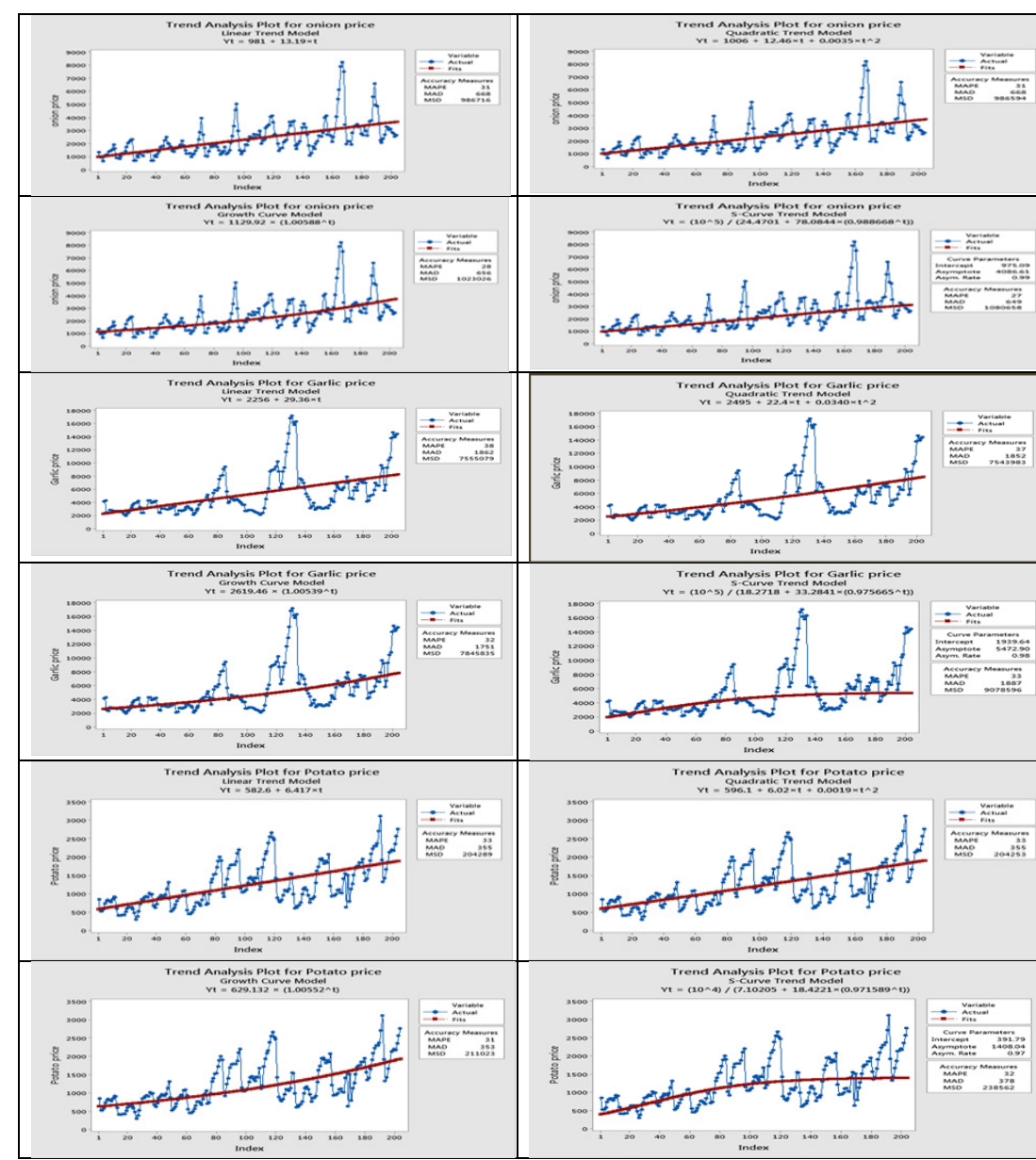

Figure 1. Trend analysis model for regarding the prices of agricultural products, from January 2000 to December 2016. 


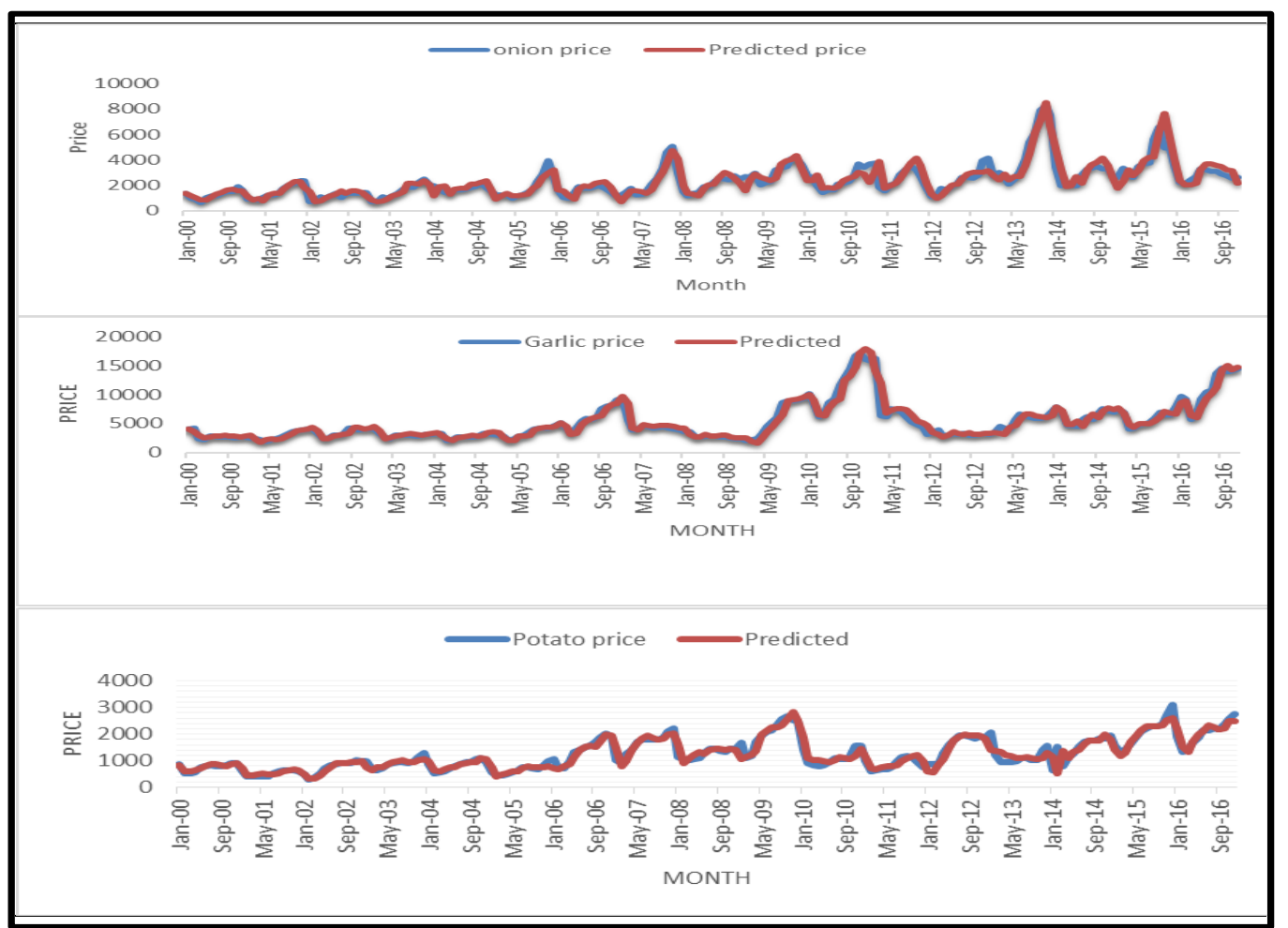

Figure 2. Cross-section line graph for the measure of comparison the price between actual wholesale price and predicted wholesale price $(\mathrm{Tk} / 100 \mathrm{~kg})$ for onion, garlic and potato, January 2000 to December 2016.

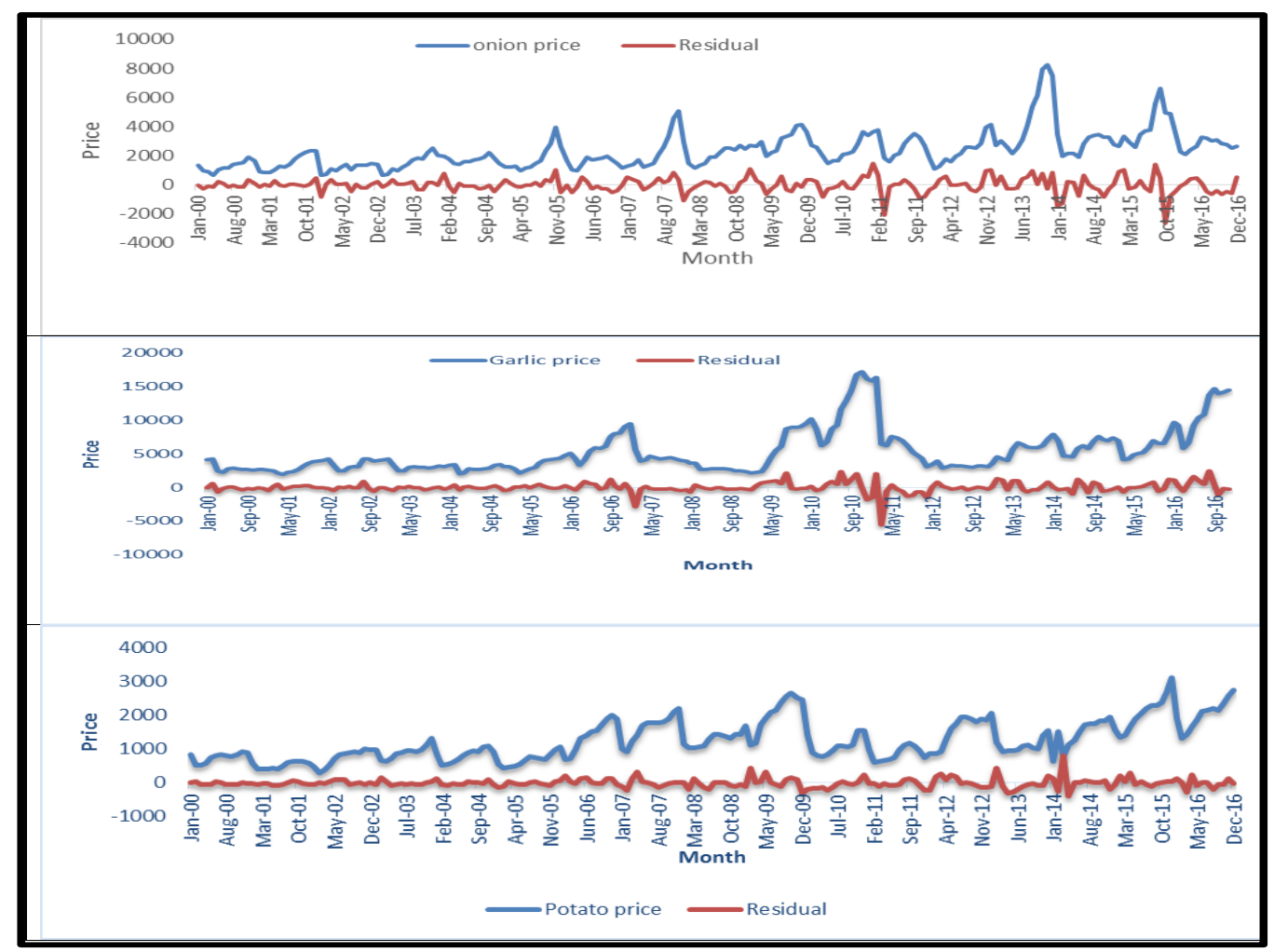

Figure 3. Comparison between the predicted prices and residuals for three selected agricultural products from January 2000 to December 2016. 


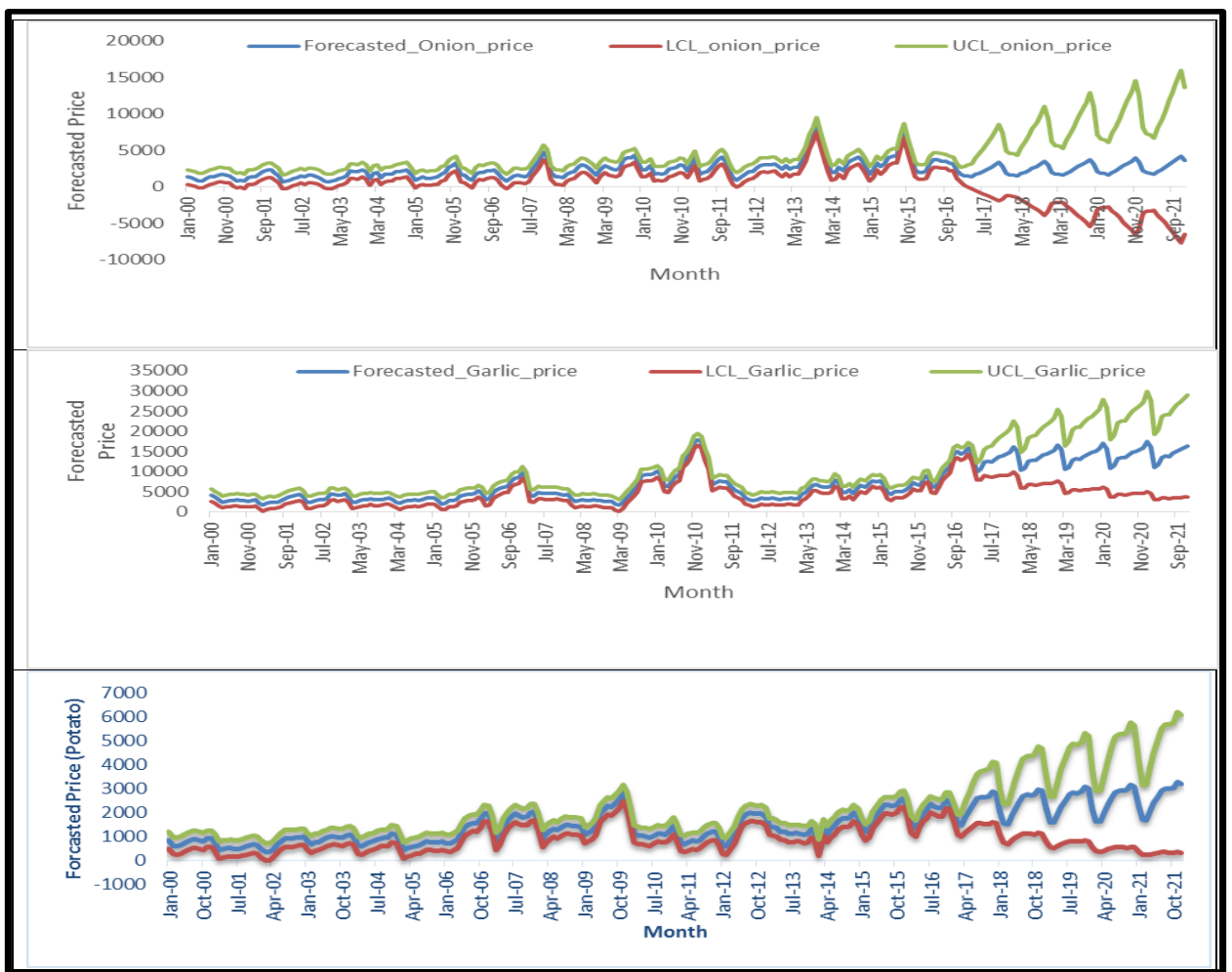

Figure 4. Forecasted prices of three agricultural products (Potato, Onion and Garlic) in Bangladesh, From January 2017 to December 2021.

January 2000 to December 2016. The forecasted prices are clearly shown upturn and downturn pattern like as the previous seasonal cyclical pattern graph. Therefore, we can conclude that accurate forecasting has been completed using data accuracy measurement and estimation process through comparison between actual price and predicted price and also predicted price and residual.

\section{Conclusion}

This study showed that exponential growth model was appropriate for forecasting future estimates of the prices of three agricultural products in Bangladesh based on the lowest values of the forecasting errors. The forecast values of the three selected agricultural products clearly showed the increasing trend. Therefore, forecasting prices of these three crops could enable the policy makers and government to take wiser steps for attaining price equilibrium to maintain the demand and supply in the market. Furthermore, based on these forecasting price information, both the seller and buyer of these products could be equally benefitted and the producers are expected to earn maximum profits from their products.

\section{References}

Abid SN, Jamal MZ, Zahid S. (2018): Exponential growth model for forecasting of area and production of potato crop in Pakistan. Pakistan Journal of Agricultural Research 31(1): 24-28.
Akhter MW, Jaim MH. (2002). Changes in the major food grains production in Bangladesh and their sources during the period from $1979 / 80$ to $1998 / 99$. The Bangladesh Journal of Agricultural Economics 25(1): 1-16.

Akhter R. (2013). Forecasting of rice production in Bangladesh. Research Journal of Agriculture and Forestry Sciences 1(7): 15-17.

Barua P, Alam S. (2000). Growth, price instability and flexibility of major crops in Bangladesh. The Bangladesh Journal of Agricultural Economics 23(1\&2): 103-114.

BBS. (2009). Bangladesh Bureau of Statistics, Statistical Yearbook of Bangladesh-2002. Statistics Division, Ministry of Planning, Government of the People`s Republic of Bangladesh, Dhaka.

BBS. (2010). Bangladesh Bureau of Statistics, Statistical Yearbook of Bangladesh-2002. Statistics Division, Ministry of Planning, Government of the People`s Republic of Bangladesh, Dhaka.

BBS. (2014). Bangladesh Bureau of Statistics, Statistical Yearbook of Bangladesh-2002. Statistics Division, Ministry of Planning, Government of the People`s Republic of Bangladesh, Dhaka.

Gujarati DN. (2016). The Analysis of Time series: An introduction. 6th edition, Chapman and Hall/CRC Press, Boca Raton, FL, US. 
Hassan MF, Islam MA, Imam MF, Sayem SM. (2013). Forecasting coarse rice prices in Bangladesh, Department of Agricultural Statistics, Bangladesh Agricultural University. Agriculture 22(1\&2): 193 - 201.

Jabber MA, Jones RP. (1997). The Growth of MV rice production and adoption in Bangladesh. The Bangladesh Journal of Agricultural Economics 20(2): 1-19.

Karim M, Awal M, Akter M. (2010). Forecasting of wheat production in Bangladesh. Bangladesh Journal of Agricultural Research 35(1): 17-28.

Khan AS, Masood, MA. 2014. Trend analysis and forecasting of maize area and production in Khyber Pakhtunkhwa, Pakistan. European Academic Research 2(4): 4653-4664.
Rahman NMF, Rahman MM, Baten, MA. (2013). Modeling for growth and forecasting of pulse production in Bangladesh. Research Journal of Applied Sciences, Engineering and Technology 5(24): 5578-5587.

Rahman, NMF, Aziz, MA, Rahman MM, Mohammad M. (2013). Modeling on Grass Pea and Mung Bean Pulse Production in Bangladesh Using ARIMA Model. IOSR Journal of Agriculture and Veterinary Science 6(1): 20-31. 